\title{
Extended lymphadenectomy benefits patients with borderline resectable pancreatic head cancer -- a single-center retrospective study
}

Jiqiao Zhu

Beijing Chaoyang Hospital

Shao-Cheng Lyu

Beijing Chaoyang Hospital

Jing Wang

Beijing Chaoyang Hospital

Xian-Liang Li

Beijing Chaoyang Hospital

Ren Lang

Beijing Chaoyang Hospital

Qiang He ( $\sim$ heqiang349@sina.com )

Beijing Chaoyang Hospital

\section{Research}

Keywords: pancreaticoduodenectomy, pancreatic head cancer, standard lymphadenectomy, extended lymphadenectomy

Posted Date: October 2nd, 2020

DOl: https://doi.org/10.21203/rs.3.rs-84126/v1

License: (c) (1) This work is licensed under a Creative Commons Attribution 4.0 International License. Read Full License 


\section{Abstract}

Background: Whether standard lymphadenectomy or extended lymphadenectomy should be performed is still under debate during pancreaticoduodenectomy (PD). We aimed to compare their morbidity and mortality rates among patients with pancreatic head cancer $(\mathrm{PHC})$.

Material and methods: In this retrospective study, a total of 322 patients were enrolled. According to the scope of intraoperative lymph node dissection, patients were divided into extended lymphadenectomy group $(n=120)$ and standard lymphadenectomy group $(n=202)$. Based on the resectability of the tumor, there were 198 cases of resectable PHC and 124 cases of boardline resectable PHC, respectively, in which further stratified analysis was carried out according to the extent of lymph node dissection.

Results: All patients completed the operation successfully, with a perioperative morbidity rate of $27.9 \%$ and mortality rate of $0.9 \%$. As for the overall patients, patients in the extended lymphadenectomy group had higher NLR, longer operation time, more intraoperative blood loss, lymph node dissection and patients with BRPHC. $(\mathrm{P}<0.05)$ The 1-, 2- and 3-year overall survival rates of patients with extended lymphadenectomy and standard lymphadenectomy were $71.9 \%, 50.6 \%, 30.0 \%$ and $70.0 \%, 32.9 \%, 21.5 \%$, respectively. ( $P=0.068)$ With regards to patients with $B R P H C$, the number of lymph node dissection in the extended lymphadenectomy group was more, $(P<0.05)$ and the $1-, 2$ - and 3-year overall survival rates of patients with extended lymphadenectomy and standard lymphadenectomy were $60.7 \%, 43.3 \%, 27.4 \%$ and $43.2 \%, 17.7 \%, 17.7 \%$, respectively. $(P=0.007)$

Conclusions: Patients with BRPHC tended to have vast lymph node metastasis. Extended lymphadenectomy can improve their long-term survival.

\section{Introduction}

Pancreatic cancer is becoming one of the most common cause of cancer mortality, whose incidence has increased in the past decade despite a decrease in incidence rates for other cancers (1). Although considerable progress has been made to improve the survival rate surgical resection remains the only potential curative method for patients with pancreatic cancer (2-4). Notably, lymphadenectomy, which is a powerful prognostic factor after pancreaticoduodenectomy (PD) that is independent of the histology, has been strongly suggested to achieve the potential cure when pancreatic cancer is suspected $(5,6)$. At present, whether standard lymphadenectomy or extended lymphadenectomy should be performed is still under debate. Ishikawa $\mathrm{O}$ et al reported extended clearance of regional lymph nodes and soft tissue could significantly prolong the survival without increasing the morbidity rate (7). In contrast, Jang JY et al found extended resection failed to improve oncologic efficacy or long-term survival compared with standard resection (8). Whereas, Pedrazzoli $\mathrm{S}$ et al did notice a trend toward longer survival after extended lymphadenectomy instead of standard lymphadenectomy in spite of similar overall survival rates between the two groups (9). Therefore, it is the surgeons' major concern to determine their efficacy among these patients. 
Moreover, previous studies focused on all patients with pancreatic head cancer without distinguishing their stages, who actually had different tumor biology and lymph node status $(10,11)$. Since it is really difficult to thoroughly assess the extent of positive lymph nodes in the preoperative and intraoperative periods due to currently limited clinical technology, we conducted a retrospective analysis in terms of resectability including resectable and borderline resectable pancreatic head cancer (BRPHC) recommended by the National Comprehensive Cancer Network (NCCN) guidelines (12). We aimed to compare the morbidity and mortality rates between extended lymphadenectomy and standard lymphadenectomy.

\section{Materials \& Methods}

\section{Ethics approval and consent to participate:}

The study complied with the Declaration of Helsinki and was approved by the Ethics Committee of Beijing Chaoyang Hospital (No.2020-D.-309-2). The participants provided written informed consent to participate in this study.

\section{Inclusion and Exclusion Criteria}

The data of patients with pancreatic head carcinoma (PHC) who underwent PD in the Department of Hepatobiliary surgery of Beijing Chaoyang hospital from January 2010 to December 2019 were analyzed retrospectively. According to the relevant inclusion/exclusion criteria and NCCN guidelines, 322 patients with PHC were enrolled. (Including 198 patients with RPHC and 124 patients with BRPHC)

Inclusion criteria: (1) Patients with PHC who underwent PD from January 2010 to December 2019. (2) Aged 20 to 85 years old. (3) Assessed as RPHC or BRPHC according to the NCCN guidelines. (4) En bloc resection of tumor during operation. (5) Postoperative pathology confirmed pancreatic ductal adenocarcinoma. (6) The mode of operation and treatment strategy obtained the informed consent of patients and their families.

Exclusion criteria: (1) Unresectable condition or metastasis found during surgery. (2) Surgical rule violation. (3) Pathologic diagnosis other than conventional ductal adenocarcinoma. (4) Postoperative follow-up data were incomplete or lost to follow-up. (Fig. 1)

\section{Patients Grouping and Definition}

According to the NCCN guidelines, the patients were divided into 198 cases of RPHC and 124 cases of BRPHC. RPHC was defined as the tumor did not invade the celiac artery or vein and had no distant metastasis and BRPHC included 45 cases of tumor invading the confluence of portal vein $(2$ cases contacting celiac trunk but invading $<180$ degree), 42 cases of tumor invading superior mesenteric vein ( 3 cases contacting superior mesenteric artery but invading < 180 degree), 37 cases invading portal vein ( 2 cases contacting common hepatic artery but invading $<180$ degree). (Fig. 2) 
The lymph node grouping is named according to the Japanese Society of Hepato-Biliary-Pancreatic Surgery. (13) According to the range of intraoperative lymph node dissection, the patients were divided into extended lymph node dissection group and standard lymph node dissection group, and differences in the extent of resection are summarized in Table 1. Surgical outcomes such as intraoperative blood loss, operation time, curative resection (R0), postoperative complication and so forth were collected. RO was defined as a specimen with clear resection margins, tumor cell was not found within $1 \mathrm{~mm}$ distance from margin. Postoperative complications were graded according to the Clavien-Dindo classification. (14) Drain amylase of $>3$ times serum amylase after the third postoperative day, as defined by ISGPS (International Study Group of Pancreatic Surgery), was defined as pancreatic fistula. (15) 
Table 1

Summary of Difference of the Extent of Surgical Dissection According to the Study Group

\begin{tabular}{|c|c|c|}
\hline Location & $\begin{array}{l}\text { Standard } \\
\text { Pancreatectomy }\end{array}$ & $\begin{array}{l}\text { Extended } \\
\text { Pancreatectomy }\end{array}$ \\
\hline Superior pyloric (5) & 0 & 0 \\
\hline Inferior pyloric (6) & 0 & 0 \\
\hline Common hepatic artery & Partial (8a) & 0 \\
\hline Anterior $\mathrm{CHA}(8 \mathrm{a})$ & 0 & 0 \\
\hline Posterior CHA (8p) & $\mathrm{x}$ & 0 \\
\hline Celiac axis (9) & $\mathrm{x}$ & 0 \\
\hline Hepatoduodenal ligament & Partial $(12 b, 12 c)$ & 0 \\
\hline proper hepatic artery (12a) & $x$ & 0 \\
\hline bile duct (12b) & 0 & 0 \\
\hline cystic duct (12c) & 0 & 0 \\
\hline portal vein $(12 p)$ & $\mathrm{x}$ & 0 \\
\hline Posterior pancreaticoduodenal (13) & 0 & 0 \\
\hline SMA & $\mathrm{x}$ & 0 \\
\hline Origin of SMA (14a) & $\mathrm{x}$ & 0 \\
\hline Right side of SMA (14b) & $\mathrm{x}$ & 0 \\
\hline Anterior SMA at middle colic (14c) & $\mathrm{X}$ & 0 \\
\hline Left side of SMA (14d) & $\mathrm{x}$ & 0 \\
\hline Aortocaval nodes (16) & $\mathrm{x}$ & 0 \\
\hline Celiac to left renal vein (16a2) & $\mathrm{x}$ & 0 \\
\hline left renal vein to IMA (16b1) & $\mathrm{x}$ & 0 \\
\hline Anterior pancreaticoduodenal (17) & 0 & 0 \\
\hline
\end{tabular}

Index Analysis and Follow-up Strategy 
The clinical and pathological data were extracted from the medical records, and the perioperative data of different groups were compared. The frequency of postoperative follow-up: 1 and 3 months after operation, once every 3 months within 2 years, and once every half a year for more than 2 years. The end points of follow-up were tumor recurrence and death. The contents of follow-up mainly included blood examination (blood routine, blood biochemistry, tumor markers, etc) and imaging examination (abdominal enhanced CT, pulmonary CT, ECT, etc), follow-up treatment, tumor recurrence and survival, and compared the long-term prognosis of patients in different groups.

\section{Statistical Analysis}

Results are presented as mean \pm standard error of the mean. Nominal data were compared using $\chi 2$ tests and continuous variables using Student $t$ tests. Survival outcomes were calculated using the KaplanMeier method and compared using the log-rank test. Only variables statistically significant by univariate analysis were included in the multivariate analysis, which was performed using a Cox proportional hazards regression model. All statistical analyses were performed using SPSS, version 22.0 (IBM), with 2sided $P$ values less than 0.05 considered statistically significant.

\section{Results}

\section{Clinical Characteristics and Outcomes}

A total of patients with pancreatic head cancer were identified. 3 patients died in perioperative period, with a perioperative mortality rate of $0.9 \%$, and the reason for the death was grade $\mathrm{C}$ pancreatic fistula complicated with abdominal hemorrhage. 120 patients with extended dissection and 202 patients with standard dissection were performed according to the extent of lymph node dissection. According to the location of the vein invaded by the tumor, 124 patients with borderline resectability underwent allogeneic vascular replacement after invasive vascular resection in 87 cases, end-to-end anastomosis in 25 cases, and direct suture after wedge resection in 12 cases. The intraoperative blood loss was $500(400,1000)$ $\mathrm{ml}$, blood transfusion was performed in 108 patients (32.5\%), and the operation time was $(9.8 \pm 2.9) \mathrm{h}$.

\section{Perioperative condition}

Postoperative complications occurred in 90 cases, with a complication rate of $27.9 \%$. Biochemical fistula occurred in 29 cases (9.0\%), B pancreatic fistula in 8 cases (2.5\%), C pancreatic fistula in 5 cases $(1.6 \%)$, diarrhea in 32 cases (9.9\%), DGE (disturbance of gastric emptying) in 30 cases (9.3\%), abdominal infection in 17 cases (5.3\%), abdominal hemorrhage in 13 cases (4.0\%), biliary fistula in 6 cases (1.9\%), pulmonary infection in 5 cases $(1.6 \%)$, gastrointestinal bleeding in 3 cases $(0.9 \%)$. There were 2 cases of intestinal fistula $(0.6 \%), 2$ cases of portal vein thrombosis $(0.6 \%)$ and 1 case of pulmonary embolism $(0.3 \%)$. The median postoperative hospital stay was $17(14,23)$ days $(7 \sim 106 \mathrm{~d})$.

All patients were confirmed as pancreatic ductal adenocarcinoma by pathological examination. Among them, the degree of tumor differentiation: moderately differentiated in 209 cases (64.9\%), poorly differentiated in 93 cases (28.9\%), and highly differentiated in 20 cases $(6.2 \%)$; tumor size: $(3.8 \pm 1.6) \mathrm{cm}$ (range: $1.0 \sim 10.0 \mathrm{~cm}$ ). The average number of lymph nodes detected was $(21.2 \pm 12.1)$ (range: $5 \sim 86$ ), 
positive lymph nodes in 208 cases (64.6\%), positive number of lymph nodes in $2(0,4)$ (range $0 \sim 22$ ), and MLNR (metastatic lymph node ratio) was $0.09(0,0.24)$ (range $0 \sim 0.76)$. Radical resection (R0) was achieved in 301 cases (93.5\%), pancreatic cutting edge was positive in 8 cases $(2.5 \%)$, pancreatic circumferential margin was positive in 7 cases $(2.2 \%)$, pancreatic uncinate process margin was positive in 4 cases $(1.2 \%)$, and portal sulcus margin was positive in 2 cases $(0.6 \%)$.

\section{Survival Data and Recurrence}

The follow-up period was up to June 2020, with a median follow-up period of 51 months. During this period, 107 patients (33.2\%) received adjuvant chemotherapy for 1 to 8 cycles. The overall median disease-free survival time of the patients was 15 months (Fig. 3-A) and the overall median survival time of the patients was 19 months. (Fig. 3-B).

\section{Comparison of patients with different lymph node dissection groups}

The comparison of perioperative general data between the extended dissection group and the standard dissection group was shown in Table 2. It can be seen that the patients in the extended dissection group had higher NLR, longer operation time, more intraoperative blood loss, more lymph node dissection and more patients with borderline resectability. $(P<0.05)$ The comparison of postoperative morbidity between two groups was shown in Table 3. It can be seen that the incidence of diarrhea in the extended dissection group was higher than that in the standard dissection group $(P<0.05)$ and there were no statistically significant differences in other perioperative complication rates and mortality rate. $(P>0.05)$ 
Table 2

Demographic and Pathologic Findings Between two Groups

\begin{tabular}{|c|c|c|c|}
\hline Variables & $\begin{array}{l}\text { Standard }(n= \\
120)\end{array}$ & Extended $(n=202)$ & $\mathbf{P}$ \\
\hline Gender (M/F) & $67 / 53$ & $114 / 88$ & 0.916 \\
\hline Age, mean $\pm S D, y r$ & $62.8 \pm 10.1$ & $62.9 \pm 10.2$ & 0.931 \\
\hline Diabetes $(\mathrm{Y} / \mathrm{N})$ & $46 / 74$ & $66 / 136$ & 0.303 \\
\hline $\operatorname{PBD}(\mathrm{Y} / \mathrm{N})$ & 19/101 & $37 / 165$ & 0.570 \\
\hline NLR & $1.8(1.3,2.4)$ & $1.6(1.2,2.1)$ & 0.039 \\
\hline $\mathrm{TB}(\mu \mathrm{mol} / \mathrm{L})$ & $52.4(10.3,138.8)$ & $23.3(10.2,123.1)$ & 0.136 \\
\hline $\mathrm{CEA}(\mathrm{ng} / \mathrm{ml})$ & $2.5(1.8,5.0)$ & $3.4(1.7,5.5)$ & 0.235 \\
\hline CA19-9 (U/ml) & $\begin{array}{l}145.4(43.9 \\
538.6)\end{array}$ & $\begin{array}{l}212.6(48.7 \\
1008.0)\end{array}$ & 0.072 \\
\hline Tumor size, mean $\pm \mathrm{SD}, \mathrm{cm}$ & $3.8 \pm 1.8$ & $3.8 \pm 1.5$ & 0.960 \\
\hline Tumor differentiation (poor/moderate/high) & $29 / 85 / 6$ & $64 / 124 / 14$ & 0.228 \\
\hline $\begin{array}{l}\text { Tumor resectability (resectable/borderline } \\
\text { resectable) }\end{array}$ & $49 / 71$ & $149 / 53$ & 0.000 \\
\hline Neoadjuvant chemotherapy $(\mathrm{Y} / \mathrm{N})$ & $14 / 106$ & $13 / 189$ & 0.102 \\
\hline Intraoperative blood loss(ml) & $600(400,800)$ & $550(400,800)$ & 0.883 \\
\hline Blood transfusion $(\mathrm{Y} / \mathrm{N})$ & $43 / 77$ & $65 / 137$ & 0.502 \\
\hline OP time, mean $\pm S E M, h$ & $10.9 \pm 3.0$ & $9.1 \pm 2.6$ & 0.000 \\
\hline LN metastasis (+/-) & $74 / 46$ & $134 / 68$ & 0.397 \\
\hline Total retrieved LNs & $21(16,30)$ & $16(11,24)$ & 0.000 \\
\hline Positive LNs & $3(1,6)$ & $1(0,4)$ & 0.000 \\
\hline MLNR & $0.13(0,0.29)$ & $0.07(0,0.20)$ & 0.013 \\
\hline Resection margin (R0/R1) & $115 / 5$ & $186 / 16$ & 0.187 \\
\hline Postoperative chemotherapy $(\mathrm{Y} / \mathrm{N})$ & $49 / 71$ & $85 / 117$ & 0.826 \\
\hline
\end{tabular}


Table 3

Morbidity and Mortality Between two Groups

\begin{tabular}{|llll|}
\hline Variables & Standard $(\mathbf{n}=120)$ & Extended $(\mathbf{n}=\mathbf{2 0 2})$ & $\mathbf{P}$ \\
\hline Postoperative hospital stay $(\mathrm{d})$ & $17(14,23)$ & $17(14,23)$ & 0.896 \\
\hline In-hospital death & 1 & 2 & 0.647 \\
\hline Complications & 35 & 55 & 0.708 \\
\hline Biochemical fistula & 13 & 13 & 0.161 \\
\hline Pancreatic fistula & 3 & 5 & 0.722 \\
Grade B & 2 & 3 & 0.735 \\
Grade C & 8 & 24 & 0.131 \\
\hline DGE & 22 & 10 & 0.001 \\
\hline Diarrhea & 8 & 9 & 0.391 \\
\hline Intra-abdominal infection & 3 & 10 & 0.431 \\
\hline Abdominal hemorrhage & 2 & 4 & 0.822 \\
\hline Biliary anastomotic leak & & & \\
\hline DGE, delayed gastric emptying. & & & \\
\hline
\end{tabular}

The median disease-free survival time of patients with extended lymph node dissection and standard lymph node dissection was 16 months and 15 months, respectively. The 1 -, 2-and 3-year disease-free survival rates were $61.4 \%, 40.7 \%, 29.0 \%$ and $57.2 \%, 29.3 \%$ and $20.8 \%$, respectively. ( $P=0.125$, Fig. 4-A) And the overall median survival time of patients with extended lymph node dissection and standard lymph node dissection was 25 months and 18 months, respectively. The 1 -, 2-and 3-year overall survival rates were $71.9 \%, 50.6 \%, 30.0 \%$ and $70.0 \%, 32.9 \%, 21.5 \%$, respectively $(P=0.068$, Fig. 4-B).

\section{Comparison of patients with RPHC by different lymph node dissection groups}

The comparison of perioperative general data between the extended dissection group and the standard dissection group was shown in Table 4. It can be seen that the NLR value of the extended dissection group was higher, the operation time was longer, and the number of lymph node dissection wais more than that of the standard dissection group $(P<0.05)$. The comparison of postoperative complications between two groups was shown in Table 5. It can be seen that the incidence of diarrhea in the extended lymph node dissection group was also higher than that in the standard lymph node dissection group $(\mathrm{P}<$ 0.05). There was no significant difference in the incidence and mortality of other perioperative complications. $(P>0.05)$ 
Table 4

Demographic and Pathologic Findings Between two Groups in Patients with RPHC

\begin{tabular}{|llll|}
\hline Variables & Standard $(\mathbf{n}=49)$ & Extended $(\mathbf{n}=149)$ & $\mathbf{P}$ \\
\hline Gender (M/F) & $31 / 18$ & $92 / 57$ & 0.849 \\
\hline Age, mean \pm SD, yr & $65.0 \pm 9.5$ & $63.2 \pm 10.0$ & 0.255 \\
\hline Diabetes (Y/N) & $18 / 31$ & $44 / 105$ & 0.346 \\
\hline PBD (Y/N) & $9 / 40$ & $30 / 119$ & 0.787 \\
\hline NLR & $2.0(1.5,2.5)$ & $1.6(1.2,2.2)$ & 0.045 \\
\hline TB( $\mu$ mol/L) & $86.3(12.6,124.6)$ & $24.1(10.2,160.0)$ & 0.374 \\
\hline CEA(ng/ml) & $3.1(1.3,4.4)$ & $3.4(1.6,4.8)$ & 0.229 \\
\hline CA19-9(U/ml) & $145.4(60.0,324.1)$ & $188.9(47.6,648.9)$ & 0.714 \\
\hline Tumor size, mean \pm SD, cm & $3.6 \pm 2.1$ & $3.7 \pm 1.5$ & 0.724 \\
\hline Tumor differentiation (poor/moderate/high) & $9 / 37 / 3$ & $48 / 88 / 13$ & 0.114 \\
\hline Intraoperative blood loss(ml) & $500(400,600)$ & $500(400,800)$ & 0.187 \\
\hline Blood transfusion (Y/N) & $10 / 39$ & $37 / 112$ & 0.528 \\
\hline OP time, mean \pm SEM, h & $9.3 \pm 2.3$ & $8.2 \pm 2.1$ & 0.004 \\
\hline LN metastasis (+/-) & $31 / 18$ & $92 / 57$ & 0.849 \\
\hline Total retrieved LNs & $18(14,30)$ & $15(11,22)$ & 0.045 \\
\hline Positive LNs & $1(0,3)$ & $1(0,4)$ & 0.610 \\
\hline MLNR & $0.06(0,0.17)$ & $0.07(0,0.20)$ & 0.934 \\
\hline Resection margin (RO/R1) & $49 / 0$ & $140 / 9$ & 0.172 \\
\hline Postoperative chemotherapy (Y/N) & $18 / 31$ & $61 / 88$ & 0.602 \\
\hline PBD, preoperative biliary drainage; NLR, neutrophil to lymphocyte ratio; TB, total bilirubin; CEA, & \\
\hline carcinoma embryonic antige; CA19-9, carbohydrate antigen 199; OP: operation; LN, lymph node; & \\
\hline MLNR, metastatic lymph node ratio. & & & \\
\hline
\end{tabular}


Table 5

Morbidity and Mortality Between two Groups in Patients with RPHC

\begin{tabular}{|llll|}
\hline Variables & Standard $(\mathbf{n}=49)$ & Extended $(\mathbf{n}=149)$ & $\mathbf{P}$ \\
\hline Postoperative hospital stay $(\mathrm{d})$ & $16(13,18)$ & $17(13,22)$ & 0.233 \\
\hline In-hospital death & 0 & 0 & - \\
\hline Complications & 12 & 42 & 0.614 \\
\hline Biochemical fistula & 5 & 10 & 0.624 \\
\hline Pancreatic fistula & 3 & 4 & 0.494 \\
Grade B & 0 & 0 & - \\
Grade C & & & \\
\hline DGE & 7 & 20 & 0.879 \\
\hline Diarrhea & 8 & 7 & 0.018 \\
\hline Intra-abdominal infection & 3 & 7 & 0.985 \\
\hline Abdominal hemorrhage & 0 & 7 & 0.272 \\
\hline Biliary anastomotic leak & 1 & 2 & 1.000 \\
\hline DGE, delayed gastric emptying. & & & \\
\hline
\end{tabular}

The median disease-free survival time of patients with extended lymph node dissection and standard lymph node dissection was 20 months and 17 months, respectively, and the 1 -, 2-and 3-year disease-free survival rates were $79.4 \%, 41.6 \%, 32.1 \%$ and $65.7 \%, 32.9 \%$, and $22.7 \%$, respectively ( $P=0.205$, Fig. 5 - $A$ ). The overall median survival time of patients with extended lymph node dissection and standard lymph node dissection was 25 months and 21 months, respectively, and the 1 -, 2-and 3-year overall survival rates were $87.7 \%, 60.9 \%, 33.8 \%$ and $79.1 \%, 38.9 \%, 24.6 \%$, respectively $(P=0.146$, Fig. $5-B)$.

\section{Comparison of patients with BRPHC by different lymph node dissection groups}

The comparison of perioperative general data between the extended dissection group and the standard dissection group was shown in Table 6, which shows that the number of lymph node dissection in the extended dissection group was more than that in the standard dissection group $(P<0.05)$. The comparison of postoperative complications between the two groups was shown in Table 7. It can be seen that the incidence of diarrhea in the extended dissection group was higher than that in the standard dissection group $(P<0.05)$. There was no significant difference in the incidence and mortality of other perioperative complications. $(P>0.05)$ 
Table 6

Demographic and Pathologic Findings Between two Groups in Patients with BRPHC

\begin{tabular}{|c|c|c|c|}
\hline Variables & Standard $(n=71)$ & Extended $(n=53)$ & $\mathbf{P}$ \\
\hline Gender (M/F) & $36 / 35$ & $22 / 31$ & 0.310 \\
\hline Age, mean $\pm S D$, yr & $61.3 \pm 10.2$ & $62.2 \pm 10.8$ & 0.632 \\
\hline Diabetes $(\mathrm{Y} / \mathrm{N})$ & $28 / 43$ & $22 / 31$ & 0.816 \\
\hline $\mathrm{PBD}(\mathrm{Y} / \mathrm{N})$ & $10 / 61$ & $7 / 46$ & 0.888 \\
\hline NLR & $1.7(1.3,2.2)$ & $1.5(1.3,1.8)$ & 0.098 \\
\hline $\mathrm{TB}(\mu \mathrm{mol} / \mathrm{L})$ & $21.1(9.5,128.8)$ & $33.1(11.2,137.7)$ & 0.499 \\
\hline $\mathrm{CEA}(\mathrm{ng} / \mathrm{ml})$ & $2.5(2.0,5.3)$ & $3.3(2.0,5.9)$ & 0.341 \\
\hline CA19-9(U/ml) & $195.9(43.1,693.1)$ & $215.8(45.0,1250.0)$ & 0.304 \\
\hline Tumor size, mean $\pm \mathrm{SD}, \mathrm{cm}$ & $3.8 \pm 1.6$ & $3.9 \pm 1.3$ & 0.878 \\
\hline Tumor differentiation (poor/moderate/high) & $20 / 48 / 3$ & $16 / 36 / 1$ & 0.757 \\
\hline Neoadjuvant chemotherapy $(\mathrm{Y} / \mathrm{N})$ & $14 / 57$ & $13 / 40$ & 0.521 \\
\hline Intraoperative blood loss(ml) & $600(400,950)$ & $600(400,1000)$ & 0.760 \\
\hline Blood transfusion $(\mathrm{Y} / \mathrm{N})$ & $33 / 38$ & $28 / 25$ & 0.484 \\
\hline OP time, mean \pm SEM, $\mathrm{h}$ & $12.0 \pm 2.9$ & $11.8 \pm 2.0$ & 0.647 \\
\hline LN metastasis (+/-) & $43 / 28$ & $42 / 11$ & 0.794 \\
\hline Total retrieved LNs & $24(18,32)$ & $18(13,30)$ & 0.007 \\
\hline Positive LNs & $4(2,6)$ & $2(0,4)$ & 0.001 \\
\hline MLNR & $0.17(0.08,0.31)$ & $0.13(0,0.20)$ & 0.053 \\
\hline Resection margin (R0/R1) & $66 / 5$ & $46 / 7$ & 0.251 \\
\hline Postoperative chemotherapy $(\mathrm{Y} / \mathrm{N})$ & $31 / 41$ & $24 / 29$ & 0.804 \\
\hline
\end{tabular}


Table 7

Morbidity and Mortality Between two Groups in Patients with BRPHC

\begin{tabular}{|llll|}
\hline Variables & Standard $(\mathbf{n}=\mathbf{7 1})$ & Extended $(\mathbf{n}=\mathbf{5 3})$ & $\mathbf{P}$ \\
\hline Postoperative hospital stay $(\mathrm{d})$ & $21(15,28)$ & $18(14,23)$ & 0.224 \\
\hline In-hospital death & 1 & 2 & 0.797 \\
\hline Complications & 23 & 13 & 0.340 \\
\hline Biochemical fistula & 8 & 3 & 0.443 \\
\hline Pancreatic fistula & 0 & 1 & 0.427 \\
Grade B & 2 & 3 & 0.738 \\
Grade C & 3 & 4 & 0.689 \\
\hline DGE & 14 & 3 & 0.024 \\
\hline Diarrhea & 5 & 2 & 0.699 \\
\hline Intra-abdominal infection & 3 & 3 & 0.957 \\
\hline Abdominal hemorrhage & 1 & 2 & 0.797 \\
\hline Biliary anastomotic leak & & & \\
\hline DGE, delayed gastric emptying. & & & \\
\hline
\end{tabular}

The median disease-free survival time of patients with extended lymph node dissection and standard lymph node dissection was 12 months and 8 months, respectively, and the 1 -, 2-and 3-year disease-free survival rates were $48.5 \%, 40.3 \%, 26.2 \%$ and $30.4 \%, 15.6 \%, 15.6 \%$, respectively $(P=0.026$, Fig. $6-A)$. The overall median survival time of patients with extended lymph node dissection and standard lymph node dissection was 18 months and 12 months, respectively. The 1 -, 2-and 3-year overall survival rates were $60.7 \%, 43.3 \%, 27.4 \%$ and $43.2 \%, 17.7 \%, 17.7 \%$, respectively ( $P=0.007$, Fig. 6-B).

\section{Discussion}

Lymph node status is a powerful prognostic factor in patients with pancreatic head cancer after resection as lymph node invasion occurs in a high percentage of these patients indicating poor survival (16-19). Therefore, lymphadenectomy has been recognized as an important and fundamental step during PD. A growing body of evidence shows local recurrence after conventional PD results from incomplete clearance of the lymph nodes suggesting extended lymphadenectomy may improve survival outcomes theoretically. For example, the survival rates after extended lymphadenectomy were reported to be greatly enhanced compared with those after standard lymphadenectomy $(7,20-22)$. However, recent studies found that extended resection did not have survival advantages over standard resection $(8,23-25)$. 
Consequently, it is uncertain whether extended lymphadenectomy is superior to standard lymphadenectomy in PD.

In our study, we found extended lymphadenectomy did not improve the survival in all patients with pancreatic head cancer but to cause an increase in the difficulty of surgery (prolonged operating time) as well as in the postoperative complication (high incidence of diarrhea) due to its nature. Accordingly, the number of harvested lymph nodes was larger after extended lymphadenectomy. When we further analyzed the data merely from the subgroup of patients with resectable disease, there were no difference in survival rates between extended lymphadenectomy and standard lymphadenectomy. Therefore, comparison of the number of metastatic lymph nodes did not favor extended lymphadenectomy in patients with resectable disease.

In contrast, distinguished results with respect to the survival rates were observed in patients with BRPHC. Extended lymphadenectomy improved the disease-free survival and the overall survival greatly in patients with BRPHC compared with standard lymphadenectomy. BRPHC, an intermediate stage between resectable and unresectable disease, invades the mesenteric-portal or arterial axis (26). In case of superior mesenteric-portal vein involvement, venous resection and reconstruction during pancreaticoduodenectomy (PD) can contribute to long-term survival of these patients $(27,28)$. There has been increasing evidence indicating that patients with BRPHC could reach the survival similar to patients with resectable disease following surgery (29-31). However, few studies are reported concerning lymphadenectomy in patients with BRPHC. Actually, the reasonable extent of surgery is based on the range of lymph node invasion. The number of metastatic lymph nodes increased greatly in addition to the number of total lymph nodes in this study, which meant patients with BRPHC might have a wide range of lymph node invasion. Therefore, extended lymphadenectomy might benefit these selected patients. Since vascular resection and reconstruction can significantly affect the process, operating time was similar between the subgroups.

Currently, the risk factors for extensive lymph node metastasis remain limited. In this study, we determined large tumor size, poor tumor differentiation and BRPHC were the independent predictors favoring extended lymphadenectomy. Tumor size has been repeatedly reported to be a crucial prognostic factor for patients with pancreatic cancer (32-36), in relation to positive peritoneal lavage cytology (37) and recurrence $(38,39)$. It is thought that cells within the tumor usually acquire mutations, and finally, a sub-clone that is capable of lymph node metastasis may evolve as the primary tumor grows. Feng et ai reported NEAT1 could promote PC cell proliferation and metastasis both in vitro and in vivo associating with tumor size and lymph node (40). Oshima et al found mutations in KRAS, p53 and SMAD4 were significantly associated with tumor size and lymph node metastasis (41). It is possible the extent of lymph node metastases tends to increase with tumor size $(42,43)$.

Another expected risk factor for extensive lymph node metastasis was the poor tumor differentiation which influenced the clinical outcome of patients. In essence, poor degree of tumor differentiation reflects rapid tumor progression (44), whereas there are rich lymphatic networks around the pancreas including 
the internal pancreatic lymphatics, extrapancreatic lymphatics and peripancreatic lymphatics, which make lymph node metastasis easier. Actually, differentiation of tumor cells is controlled by complex regulatory networks, which can be explained with molecular mechnism of pancreatic cancer differentiation. Xie et al reported dysregulated KLF4 expression associated with poor differentiation of pancreatic cancer (45). Milan et al determined FOXA2 regulated well- and poorly differentiated pancreatic ductal adenocarcinoma cells via interactions with transcription factors (46). Liang et al found patients with poor tumor differentiation had higher MAP4K4 expression, and consequently increased number of positive lymph nodes (47). All these data support a positive association between lymph node metastasis and poor tumor differentiation.

As borderline resectability is noted as a high risk for a margin-positive status in patients with BRPHC vascular resection and reconstruction is usually required in these patients. Nevertheless, the survival still decreases with the severity of vascular involvement (25). Surprisingly, the disease-free survival and the overall survival improved in patients with BRPHC undergoing extended lymphadenectomy in our study due to a wide range of lymph node invasion. There are two possible reasons for this phenomenon. On one hand, the superior mesenteric-portal vein invasion might occur in patients with higher rates of poor tumor differentiation (48) as well as in patients with a larger tumor size $(49,50)$, which was also confirmed in our study; on the other hand, invasions of the plexuses around the arteries are the main causes of local recurrence after resection in these patients (51). All these suggest a higher rate of lymph node metastasis. Nevertheless, local tumor control by extended lymphadenectomy cannot overcome the negative aspects of pre-existing lymph node metastasis as well as superior mesenteric-portal vein involvement, which might explain why patients with BRPHC still have lower survival rates.

Taken together, we found that patients with BRPHC tended to have vast lymph node metastasis compared with patients with resectable disease. Extensive surgery for pancreatic carcinoma should be entertained in selected patients as it can improve their long-term survival.

The main limitation of this study is that it represented the experience of a single center. The number of patients in each subgroup is relatively small, which may limit the accuracy of our assessment. Future studies, preferably random clinical trials from multi-centers, are needed to further confirm our preliminary outcomes.

\section{Conclusions}

Patients with borderline resectable pancreatic head cancer tended to have vast lymph node metastasis. Extended lymphadenectomy can improve their long-term survival.

\section{Declarations}

Ethical approval: All procedures performed in the study involving human participants were in accordance with the ethical standards of the Institutional Review Board of our institute and with the 1964 Helsinki 
declaration and its later amendments.

Informed consent: For this type of study formal consent is not required.

Funding: none

Conflict of Interest: none

\section{Authors' contributions}

Contributions: (I) Conception and design: Ji-qiao Zhu, Shao-cheng Lyu and Jing Wang; (II)Administrative support: Ren Lang, Qiang He; (III) Provision of study materials or patients: Jing Wang, Ren Lang; (IV) Collection and assembly of data: Jing Wang, Shao-cheng Lyu; (V) Data analysis and interpretation: Shaocheng Lyu, Xian-liang Li; (VI) Manuscript writing: All authors; (VII) Final approval of manuscript: All authors.

\section{References}

1. Simard EP, Ward EM, Siegel R, Jemal A. Cancers with increasing incidence trends in the United States: 1999 through 2008. CA Cancer J Clin. 2012;62(2):118-28.

2. Mizrahi JD, Surana R, Valle JW, Shroff RT. Pancreatic cancer. Lancet. 2020;395(10242):2008-20.

3. O'Reilly EM, Ferrone C. Neoadjuvant or Adjuvant Therapy for Resectable or Borderline Resectable Pancreatic Cancer: Which Is Preferred? J Clin Oncol. 2020;38(16):1757-9.

4. Nevala-Plagemann C, Hidalgo M, Garrido-Laguna I. From state-of-the-art treatments to novel therapies for advanced-stage pancreatic cancer. Nat Rev Clin Oncol. 2020;17(2):108-23.

5. Smyth EC, Fassan M, Cunningham D, Allum WH, Okines AF, Lampis A, et al. Effect of Pathologic Tumor Response and Nodal Status on Survival in the Medical Research Council Adjuvant Gastric Infusional Chemotherapy Trial. J Clin Oncol. 2016;34(23):2721-7.

6. Ghaneh P, Kleeff J, Halloran CM, Raraty M, Jackson R, Melling J, et al. The Impact of Positive Resection Margins on Survival and Recurrence Following Resection and Adjuvant Chemotherapy for Pancreatic Ductal Adenocarcinoma. Ann Surg. 2019;269(3):520-9.

7. Ishikawa O, Ohhigashi H, Sasaki Y, Kabuto T, Fukuda I, Furukawa H, et al. Practical usefulness of lymphatic and connective tissue clearance for the carcinoma of the pancreas head. Ann Surg. 1988;208(2):215-20.

8. Jang JY, Kang MJ, Heo JS, Choi SH, Choi DW, Park SJ, et al. A prospective randomized controlled study comparing outcomes of standard resection and extended resection, including dissection of the nerve plexus and various lymph nodes, in patients with pancreatic head cancer. Ann Surg. 2014;259(4):656-64.

9. Pedrazzoli S, DiCarlo V, Dionigi R, Mosca F, Pederzoli P, Pasquali C, et al. Standard versus extended lymphadenectomy associated with pancreatoduodenectomy in the surgical treatment of 
adenocarcinoma of the head of the pancreas: a multicenter, prospective, randomized study. Lymphadenectomy Study Group. Ann Surg. 1998;228(4):508-17.

10. Tsuchiya R, Oribe T, Noda T. Size of the tumor and other factors influencing prognosis of carcinoma of the head of the pancreas. Am J Gastroenterol. 1985;80(6):459-62.

11. Nagai $H$, Kuroda A, Morioka Y. Lymphatic and local spread of $T 1$ and $T 2$ pancreatic cancer. A study of autopsy material. Ann Surg. 1986;204(1):65-71.

12. Network. (NCCN) Clinical Practice Guidelines in Oncology. Pancreatic Adenocarcinoma, Version 1.20202019 [Available from: https://www.nccn.org/professionals/physician_gls/default.aspx].

13. Akihiko H, Shuichi M, Shin I, Masaru M, Masayuki O, Hiroaki S, et al. Gallbladder bed resection or hepatectomy of segments $4 a$ and 5 for $\mathrm{pT} 2$ gallbladder carcinoma: analysis of Japanese registration cases by the study group for biliary surgery of the Japanese Society of Hepato-BiliaryPancreatic Surgery. J Hepatobiliary Pancreat Sci. 2013;20(5):518-24.

14. Pierre A C, Jeffrey B, Michelle L O, Jean N V, Daniel D, Richard D S, et al. The Clavien-Dindo classification of surgical complications: five-year experience. Ann Surg. 2009;250(2):187-96.

15. Claudio B, Giovanni M, Christos D, Micheal S, Mohammad A H, Mustapha A, et al. The 2016 update of the International Study Group (ISGPS) definition and grading of postoperative pancreatic fistula: 11 Years After. Surgery. 2017;161(3):584-591.

16. Klaiber U, Schnaidt ES, Hinz U, Gaida MM, Heger U, Hank T, et al. Prognostic Factors of Survival After Neoadjuvant Treatment and Resection for Initially Unresectable Pancreatic Cancer. Ann Surg. 2019.

17. He J, Blair AB, Groot VP, Javed AA, Burkhart RA, Gemenetzis G, et al. Is a Pathological Complete Response Following Neoadjuvant Chemoradiation Associated With Prolonged Survival in Patients With Pancreatic Cancer? Ann Surg. 2018;268(1):1-8.

18. Demir IE, Jager C, Schlitter AM, Konukiewitz B, Stecher L, Schorn S, et al. R0 Versus R1 Resection Matters after Pancreaticoduodenectomy, and Less after Distal or Total Pancreatectomy for Pancreatic Cancer. Ann Surg. 2018;268(6):1058-68.

19. Kadera BE, Sunjaya DB, Isacoff WH, Li L, Hines OJ, Tomlinson JS, et al. Locally advanced pancreatic cancer: association between prolonged preoperative treatment and lymph-node negativity and overall survival. JAMA Surg. 2014;149(2):145-53.

20. Satake K, Nishiwaki H, Yokomatsu H, Kawazoe Y, Kim K, Haku A, et al. Surgical curability and prognosis for standard versus extended resection for T1 carcinoma of the pancreas. Surg Gynecol Obstet. 1992;175(3):259-65.

21. Manabe T, Ohshio G, Baba N, Miyashita T, Asano N, Tamura K, et al. Radical pancreatectomy for ductal cell carcinoma of the head of the pancreas. Cancer. 1989;64(5):1132-7.

22. Naganuma T, Isaji S, Kawarada Y. Staging and extended resection for pancreatic cancer. Pancreas. 1998;16(3):355-62.

23. Farnell MB, Pearson RK, Sarr MG, DiMagno EP, Burgart LJ, Dahl TR, et al. A prospective randomized trial comparing standard pancreatoduodenectomy with pancreatoduodenectomy with extended 
lymphadenectomy in resectable pancreatic head adenocarcinoma. Surgery. 2005;138(4):618-28; discussion 28-30.

24. Michalski CW, Kleeff J, Wente MN, Diener MK, Buchler MW, Friess H. Systematic review and metaanalysis of standard and extended lymphadenectomy in pancreaticoduodenectomy for pancreatic cancer. Br J Surg. 2007;94(3):265-73.

25. Yeo CJ, Cameron JL, Lillemoe KD, Sohn TA, Campbell KA, Sauter PK, et al. Pancreaticoduodenectomy with or without distal gastrectomy and extended retroperitoneal lymphadenectomy for periampullary adenocarcinoma, part 2: randomized controlled trial evaluating survival, morbidity, and mortality. Ann Surg. 2002;236(3):355-66; discussion 66-8.

26. Murakami Y, Satoi S, Motoi F, Sho M, Kawai M, Matsumoto I, et al. Portal or superior mesenteric vein resection in pancreatoduodenectomy for pancreatic head carcinoma. Br J Surg. 2015;102(7):837-46.

27. Nakao A, Kanzaki A, Fujii T, Kodera Y, Yamada S, Sugimoto H, et al. Correlation between radiographic classification and pathological grade of portal vein wall invasion in pancreatic head cancer. Ann Surg. 2012;255(1):103-8.

28. Zhu J, Li X, Kou J, Ma J, Li L, Fan H, et al. Proposed Chaoyang vascular classification for superior mesenteric-portal vein invasion, resection, and reconstruction in patients with pancreatic head cancer during pancreaticoduodenectomy - A retrospective cohort study. Int J Surg. 2018;53:292-7.

29. Leach SD, Lee JE, Charnsangavej C, Cleary KR, Lowy AM, Fenoglio CJ, et al. Survival following pancreaticoduodenectomy with resection of the superior mesenteric-portal vein confluence for adenocarcinoma of the pancreatic head. Br J Surg. 1998;85(5):611-7.

30. Malleo G, Maggino L, Marchegiani G, Feriani G, Esposito A, Landoni L, et al. Pancreatectomy with venous resection for $\mathrm{pT} 3$ head adenocarcinoma: Perioperative outcomes, recurrence pattern and prognostic implications of histologically confirmed vascular infiltration. Pancreatology. 2017;17(5):847-57.

31. Ravikumar R, Sabin C, Abu Hilal M, Bramhall S, White S, Wigmore S, et al. Portal vein resection in borderline resectable pancreatic cancer: a United Kingdom multicenter study. J Am Coll Surg. 2014;218(3):401-11.

32. Satoi S, Yamamoto T, Uchida K, Fujii T, Kin T, Hirano S, et al. Optimal Treatment for Octogenarians With Resectable and Borderline Resectable Pancreatic Ductal Adenocarcinoma: A Multicenter Retrospective Study. Pancreas. 2020;49(6):837-44.

33. Ueda M, Endo I, Nakashima M, Minami Y, Takeda K, Matsuo K, et al. Prognostic factors after resection of pancreatic cancer. World J Surg. 2009;33(1):104-10.

34. de Jong MC, Li F, Cameron JL, Wolfgang CL, Edil BH, Herman JM, et al. Re-evaluating the impact of tumor size on survival following pancreaticoduodenectomy for pancreatic adenocarcinoma. J Surg Oncol. 2011;103(7):656-62.

35. Petermann D, Demartines N, Schafer M. Is tumour size an underestimated feature in the current TNM system for malignancies of the pancreatic head? HPB (Oxford). 2013;15(11):872-81. 
36. Park H, An S, Eo SH, Song KB, Park JH, Kim KP, et al. Survival effect of tumor size and extrapancreatic extension in surgically resected pancreatic cancer: proposal for improved $T$ classification. Hum Pathol. 2014;45(11):2341-6.

37. Hirabayashi K, Imoto A, Yamada M, Hadano A, Kato N, Miyajima Y, et al. Positive Intraoperative Peritoneal Lavage Cytology is a Negative Prognostic Factor in Pancreatic Ductal Adenocarcinoma: A Retrospective Single-Center Study. Front Oncol. 2015;5:182.

38. Takahashi D, Kojima M, Sugimoto M, Kobayashi S, Takahashi S, Konishi M, et al. Pathologic Evaluation of Surgical Margins in Pancreatic Cancer Specimens Using Color Coding With Tissue Marking Dyes. Pancreas. 2018;47(7):830-6.

39. Lee JW, Kang CM, Choi HJ, Lee WJ, Song SY, Lee JH, et al. Prognostic Value of Metabolic Tumor Volume and Total Lesion Glycolysis on Preoperative (1)(8)F-FDG PET/CT in Patients with Pancreatic Cancer. J Nucl Med. 2014;55(6):898-904.

40. Feng Y, Gao L, Cui G, Cao Y. LncRNA NEAT1 facilitates pancreatic cancer growth and metastasis through stabilizing ELF3 mRNA. Am J Cancer Res. 2020;10(1):237-48.

41. Oshima M, Okano K, Muraki S, Haba R, Maeba T, Suzuki Y, et al. Immunohistochemically detected expression of 3 major genes (CDKN2A/p16, TP53, and SMAD4/DPC4) strongly predicts survival in patients with resectable pancreatic cancer. Ann Surg. 2013;258(2):336-46.

42. Muralidhar V, Nipp RD, Mamon HJ, Punglia RS, Hong TS, Ferrone C, et al. Association Between Very Small Tumor Size and Decreased Overall Survival in Node-Positive Pancreatic Cancer. Ann Surg Oncol. 2018;25(13):4027-34.

43. Fortner JG, Klimstra DS, Senie RT, Maclean BJ. Tumor size is the primary prognosticator for pancreatic cancer after regional pancreatectomy. Ann Surg. 1996;223(2):147-53.

44. Panzuto F, Boninsegna L, Fazio N, Campana D, Pia Brizzi M, Capurso G, et al. Metastatic and locally advanced pancreatic endocrine carcinomas: analysis of factors associated with disease progression. J Clin Oncol. 2011;29(17):2372-7.

45. Xie VK, Li Z, Yan Y, Jia Z, Zuo X, Ju Z, et al. DNA-Methyltransferase 1 Induces Dedifferentiation of Pancreatic Cancer Cells through Silencing of Kruppel-Like Factor 4 Expression. Clin Cancer Res. 2017;23(18):5585-97.

46. Milan M, Balestrieri C, Alfarano G, Polletti S, Prosperini E, Spaggiari P, et al. FOXA2 controls the cisregulatory networks of pancreatic cancer cells in a differentiation grade-specific manner. EMBO J. 2019;38(20):e102161.

47. Liang JJ, Wang H, Rashid A, Tan TH, Hwang RF, Hamilton SR, et al. Expression of MAP4K4 is associated with worse prognosis in patients with stage II pancreatic ductal adenocarcinoma. Clin Cancer Res. 2008;14(21):7043-9.

48. Song A, Liu F, Wu L, Si X, Zhou Y. Histopathologic tumor invasion of superior mesenteric vein/ portal vein is a poor prognostic indicator in patients with pancreatic ductal adenocarcinoma: results from a systematic review and meta-analysis. Oncotarget. 2017;8(20):32600-7. 
49. Ohgi $K$, Yamamoto $Y$, Sugiura $T$, Okamura $Y$, Ito $T$, Ashida R, et al. Is Pancreatic Head Cancer with Portal Venous Involvement Really Borderline Resectable? Appraisal of an Upfront Surgery Series. Ann Surg Oncol. 2017;24(9):2752-61.

50. Fancellu A, Petrucciani N, Porcu A, Deiana G, Sanna V, Ninniri C, et al. The Impact on Survival and Morbidity of Portal-Mesenteric Resection During Pancreaticoduodenectomy for Pancreatic Head Adenocarcinoma: A Systematic Review and Meta-Analysis of Comparative Studies. Cancers (Basel). 2020;12(7).

51. Sugiura T, Uesaka K, Mihara K, Sasaki K, Kanemoto H, Mizuno T, et al. Margin status, recurrence pattern, and prognosis after resection of pancreatic cancer. Surgery. 2013;154(5):1078-86.

\section{Figures}

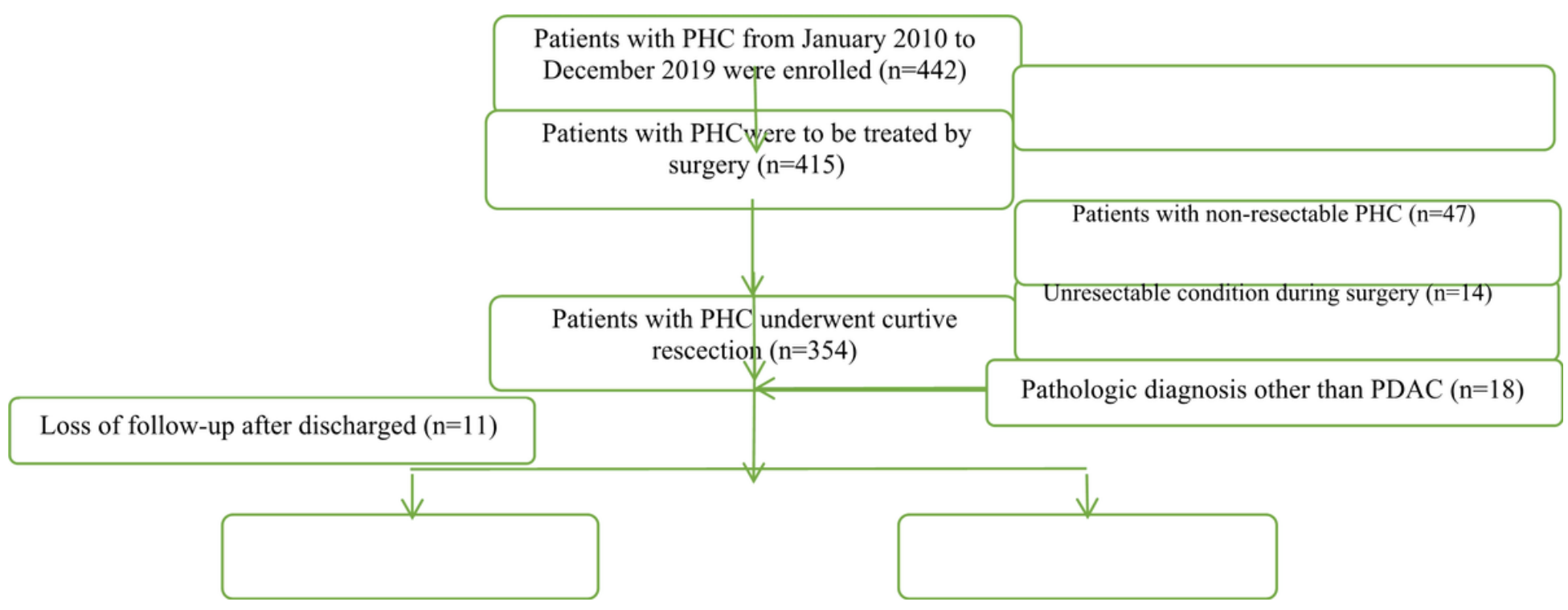

\section{Figure 1}

Screening flow chart 


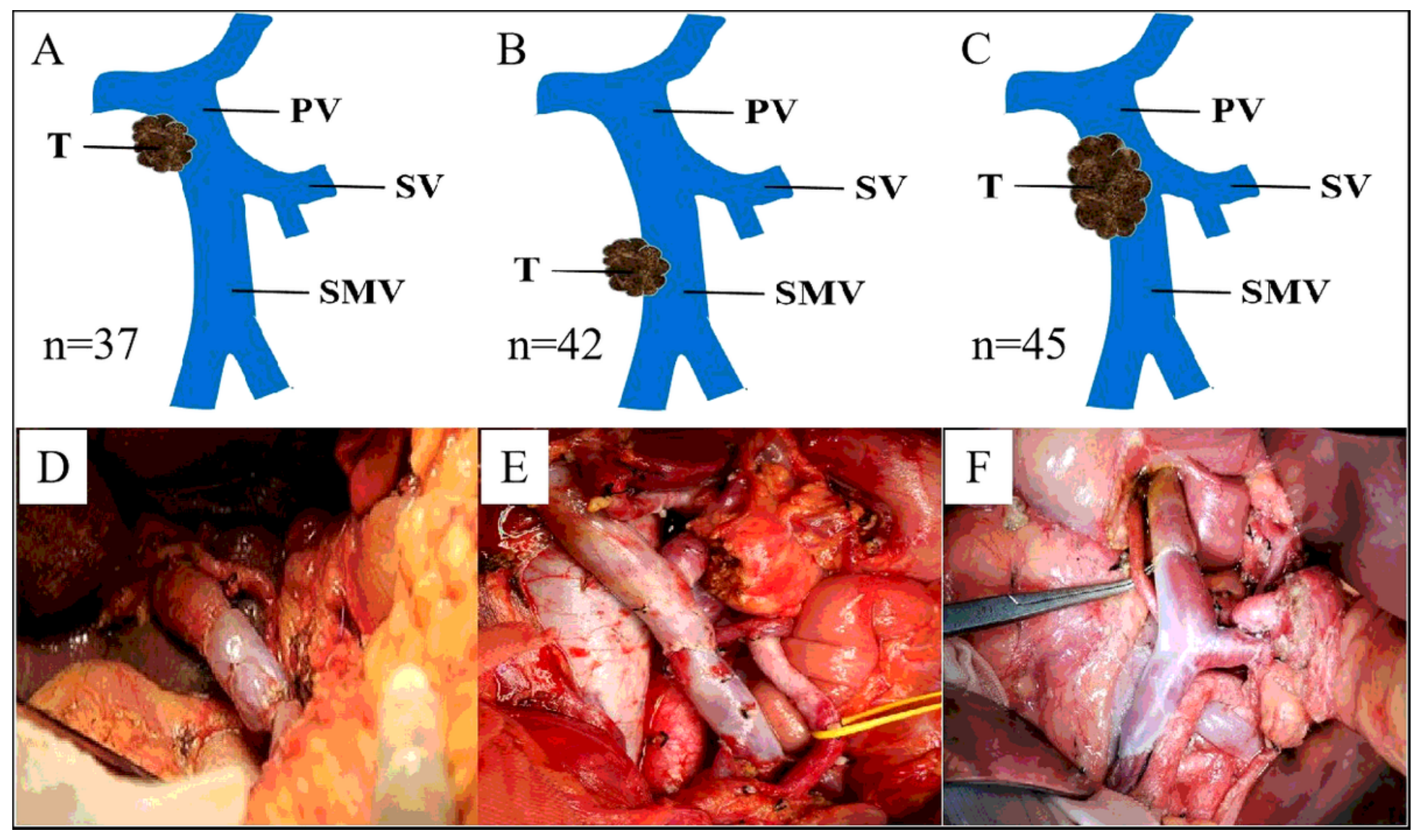

Figure 2

Venous invasion of borderline resectable pancreatic head cancer. A, Tumor invades portal vein $(n=37)$; $B$, Tumor invades superior mesenteric vein $(n=42)$; C, Tumor invades the confluence of portal vein $(n=45) ; D$, Postoperative effect of tumor invasion on portal vein; $E$, Postoperative effect of tumor invasion on superior mesenteric vein; F, Postoperative effect of tumor invasion on the confluence of portal vein 


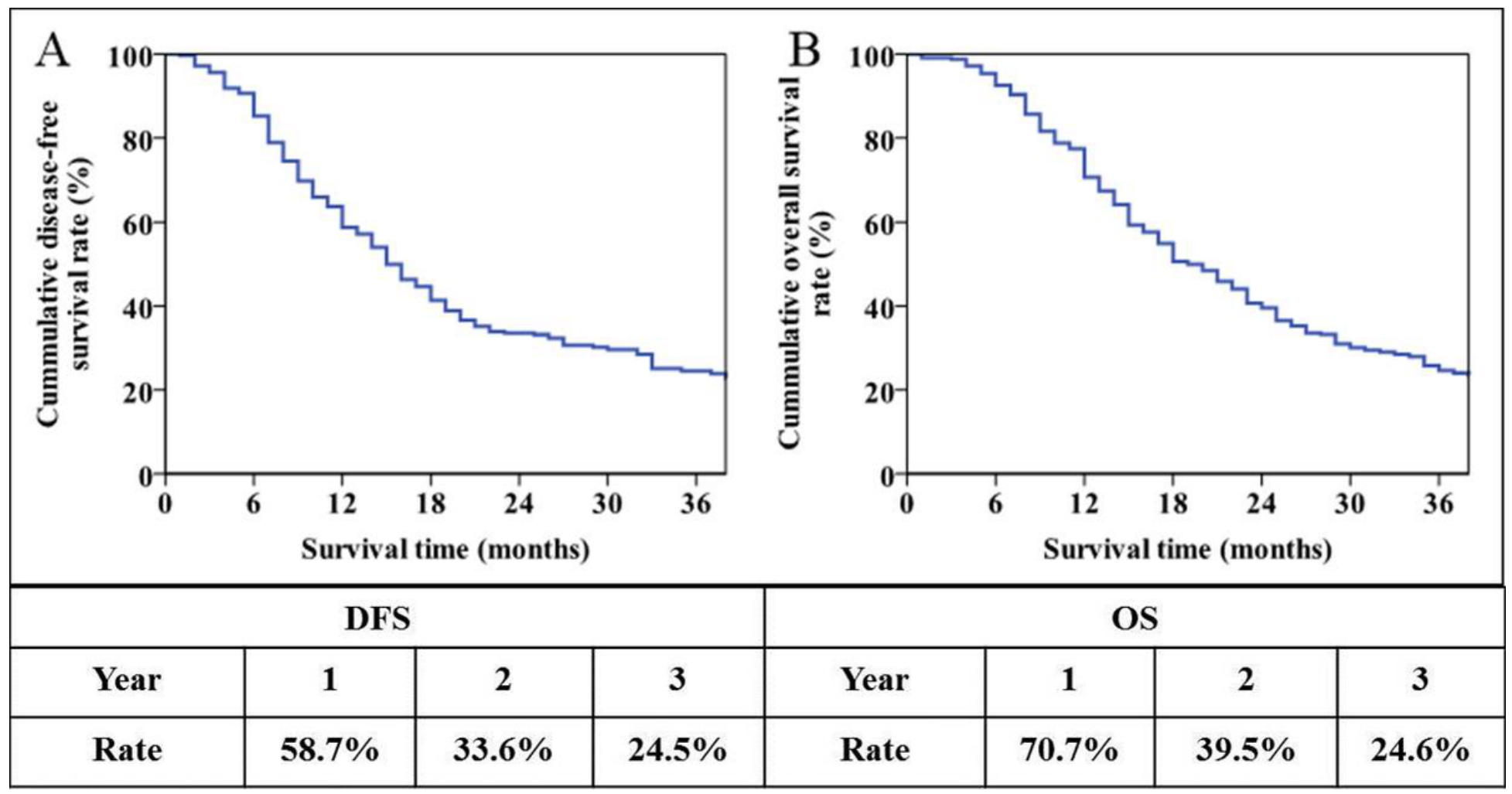

Figure 3

Overall long-term prognosis of patients. A, Disease-free survival curve of patients with pancreatic head cancer; B, Overall survival curve of patients with pancreatic head cancer

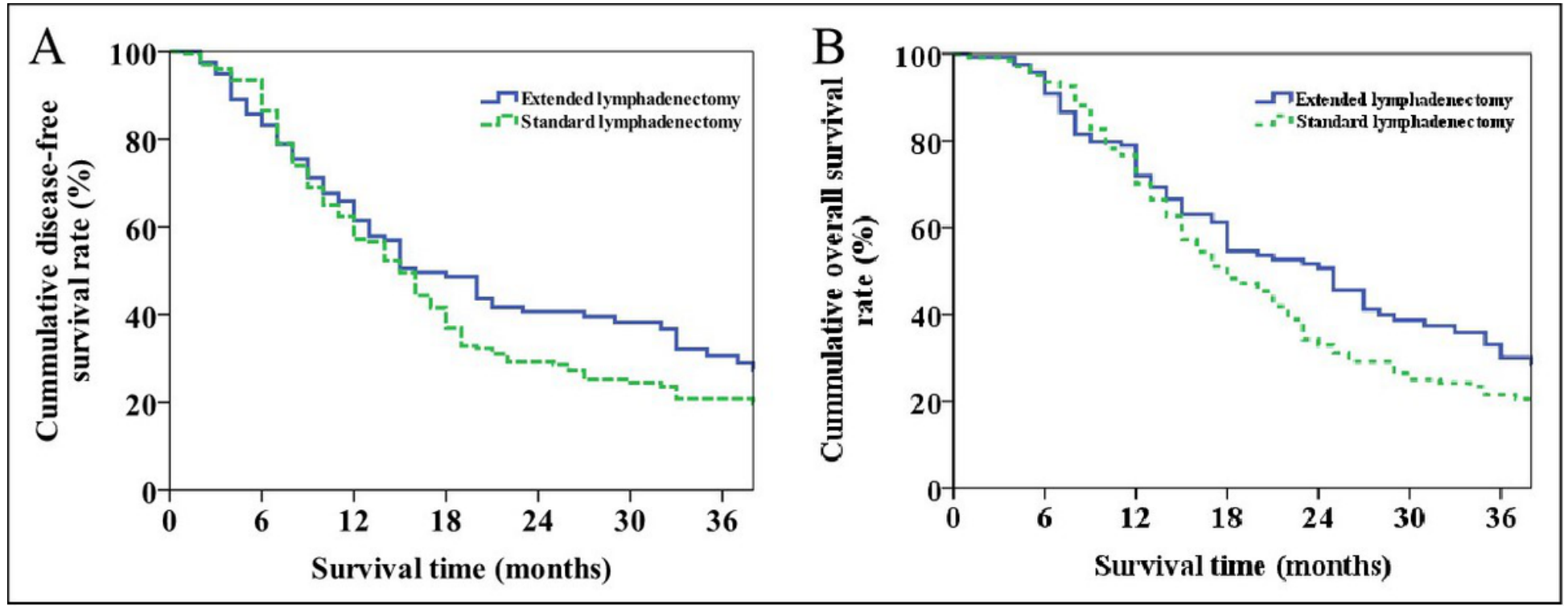

Figure 4

Overall long-term prognosis of patients with extended lymphadenectomy \& standard lymphadenectomy. A, Disease-free survival curve between two groups; B, Overall survival curve between two groups 


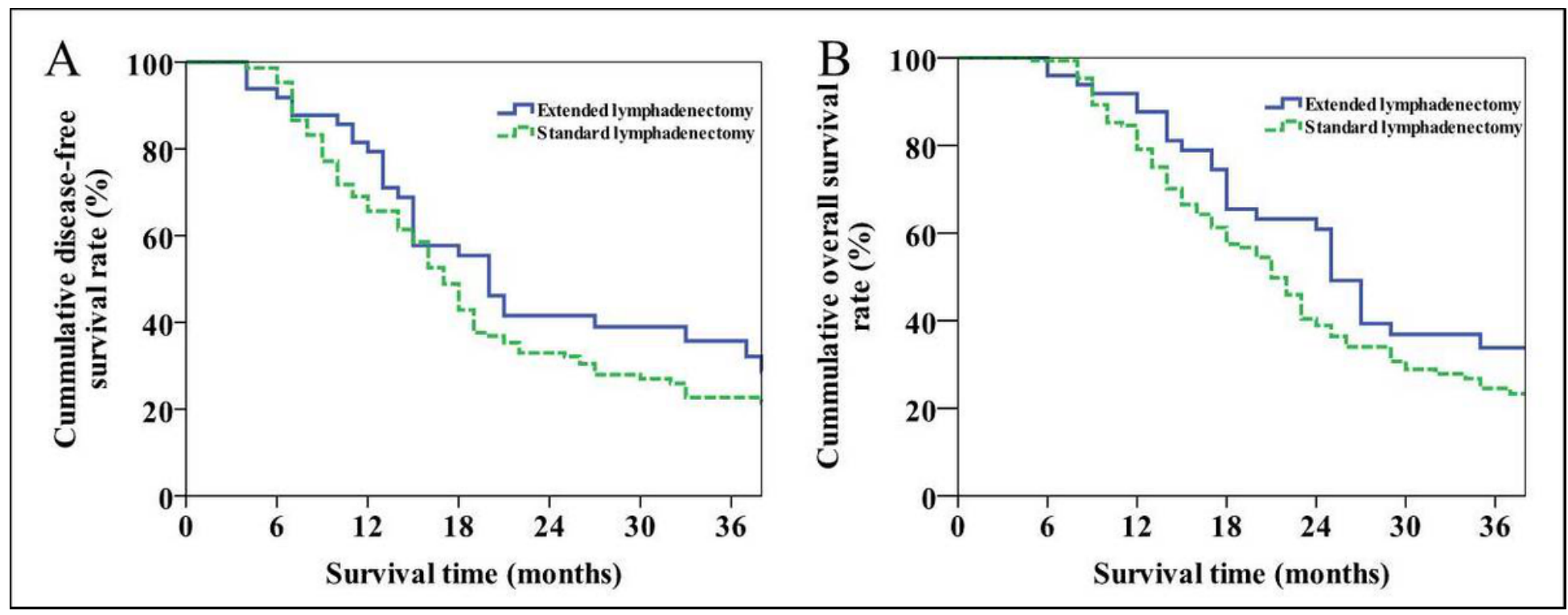

Figure 5

Overall long-term prognosis of extended lymphadenectomy \& standard lymphadenectomy in patients with resectable pancreatic head cancer. A, Disease-free survival curve between two groups; B, Overall survival curve between two groups
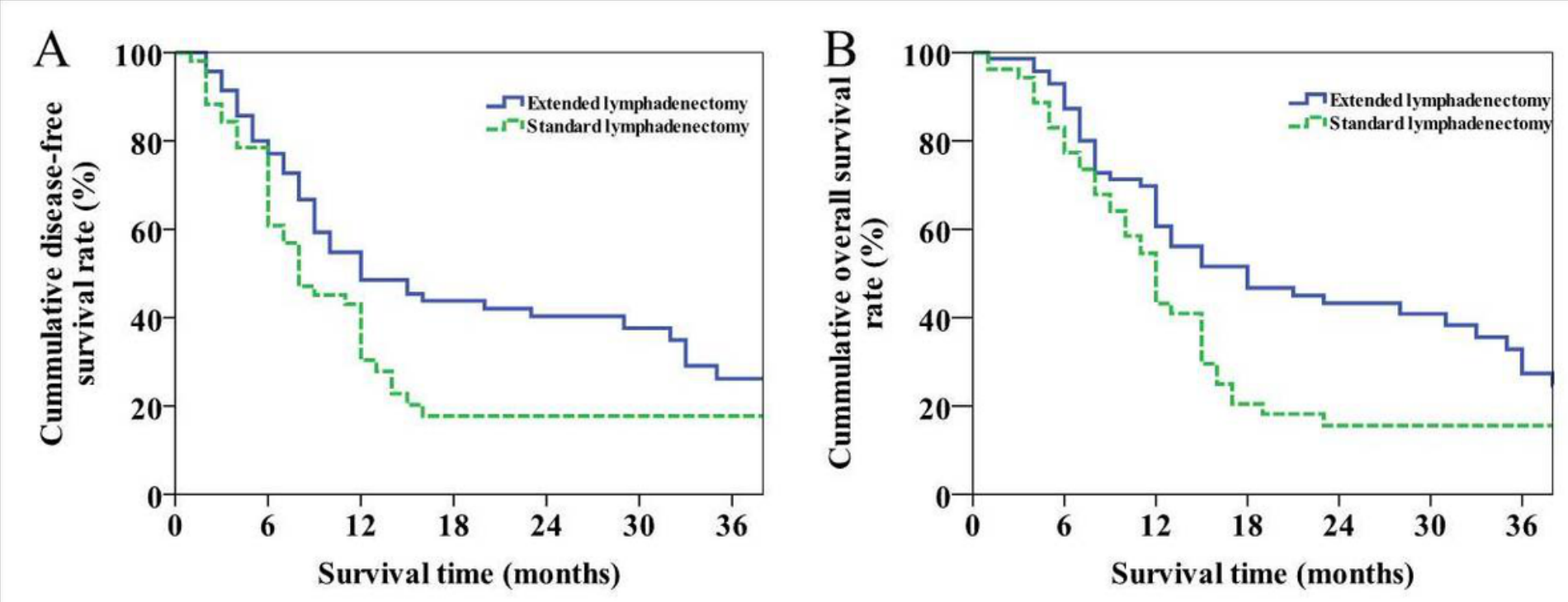

Figure 6

Overall long-term prognosis of extended lymphadenectomy \& standard lymphadenectomy in patients with borderline resectable pancreatic head cancer. A, Disease-free survival curve between two groups; B, Overall survival curve between two groups 